\title{
Developing Management Strategies for a Changing Ranching Industry
}

\section{By Barry H. Dunn}

$\mathrm{I}$ $\mathrm{n}$ addition to the traditional knowledge, skills, and tools discussed in Rangelands, the successful management of ranches and rangeland resources in the future will require new knowledge, skills, and tools. The articles from the King Ranch Institute for Ranch Management's 2007 HOLT CAT ${ }^{\circledR}$ Excellence in Ranch Management Symposium published in this issue of Rangelands are meant to do just that: provide the reader with new knowledge, skills, and tools for the successful management of the ranches and rangelands that we love and have dedicated our careers to. The first in the section, by Barry Dunn and Kimberly McCuistion, outlines the strategic planning process. Strategic management has been hailed as one of the top innovations in the business world, and although it might be new to range and ranch management, its proven track record in other applications gives it tremendous credibility. The second article, by Austin Anderson and Kimberly McCuistion, discusses the practical application of the management of rangeland for both wildlife and grazing livestock. We offer this pragmatic review of the literature as proof that at an operational level, range management doesn't have to be a matter of "either/or" but very successfully can be "both." The third article, by Doug Wilmeth, Brian Bertelsen, and Dan Probert, introduces an emerging livestock marketing alternative for ranchers: valuebased marketing alliances, and how they might be employed as part of a successful ranch management strategy. The fourth article, by Jim Mintert, outlines the emerging ethanol industry and discusses its impact on ranchers. These articles, although seemingly disconnected, are meant not only to inform the reader about specific strategies and an emerging scenario, but also to stimulate thought about other possible strategies to deal with other emerging scenarios. The challenge, then, is for ranchers and rangeland mangers to use the strategic planning process outlined in the first article to successfully navigate these dynamic times.

Author is Associate Professor, King Ranch Institute for Ranch Management, Texas Aङ $M$ University-Kingsville, and Executive Director of the King Ranch Institute for Ranch Management, Kingsville, TX 78363, USA, barry.dunn@tamuk. $e d u$ 